\title{
6- Água no Semiárido: discursos e práticas divergentes
}

\author{
Neucimeire Santos de Souza ${ }^{1}$ \\ Carla Conceição da Silva Paiva ${ }^{2}$
}

\section{Resumo}

Bem natural e recurso hídrico essencial ao consumo humano, animal e para o uso na produção agrícola, a água no Semiárido brasileiro é envolvida por interpretações distintas, o que determina a construção de dois divergentes discursos a seu respeito. Um, enfatiza a sua escassez como causa motriz da seca e da pobreza nessa região, enquanto no outro, ressalta-se o número reduzido de políticas públicas para captação e estocagem e a concentração das águas como um problema que agrava a vida dos povos no Semiárido. Face ao exposto, pretendemos compreender como essas proposições se estabelecem em jornais, livros didáticos e produções literárias, fazendo uma análise da produção imagética sobre o Semiárido. Será utilizado como base de contraponto as propostas advindas da ideia de "Combate à seca" e de "Convivência com o Semiárido brasileiro".

Palavras chave: Água; Semiárido; Livro didático, Jornalismo; Literatura.

\begin{abstract}
As a natural patrimony and essential resource for human and animal consumption and for use in agricultural production, water in Brazilian Semi-Arid is involved by different interpretations, which determines the construction of two divergent discourses about it. One emphasyzes its scarcity as the driving factor of drought and poverty in this region, while, in the other, the reduced number of public policies for capture and storage and the concentration of water in the Northeast is highlighted as a problem that aggravates the life of the people in the Semi-Arid. We intend to understand how these propositions are established in newspapers, textbooks and literary productions that deal with the region, using as our basis the proposals arising from the idea of "Combating drought" and "Living with the Semi-Arid."
\end{abstract}

Keywords: Water; Semi-Arid; Textbook; Journalism; Literature.

\section{Resumen}

Bien natural y recurso hídrico esencial para el consumo humano y animal y para el uso en la producción agrícola, el agua en el Semiárido brasileño está envuelta por interpretaciones distintas, lo que determina la construcción de dos divergentes discursos

\footnotetext{
${ }^{1}$ Estudante do oitavo período de Jornalismo em Multimeios pela Universidade do Estado da Bahia, UNEB - Departamento de Ciências Humanas, Campus III - Juazeiro-BA, Brasil. Voluntária de Iniciação Científica, no período de 01/08/2015 a 31/07/2016, dentro do subprojeto de pesquisa Signos de nordestinidade: análise da representação das identidades nordestinas presentes no cinema brasileiro e a influência euclidiana.

${ }^{2}$ Professora orientadora responsável pelo projeto.
} 
a su respecto. Uno, enfatiza su escasez como causa motriz de la sequía y la pobreza en esa región, mientras que en el otro, se resalta el número reducido de políticas públicas para captación y almacenamiento y la concentración de las aguas en el Nordeste como un problema que agrava la vida de los pueblos en el semiárido. A la vista de lo expuesto, pretendemos comprender cómo estas proposiciones se establecen en periódicos, libros didácticos y producciones literarias que versan sobre la región, utilizando como base las propuestas surgidas de la idea de "Combate a la sequía" y de "Convivencia con el Semiárido".

Palabras clave: Agua; Semiárido; Libro didáctico; Periodismo; Literatura.

\section{Introdução}

Há milhões de anos, o território que, hoje, é o Semiárido brasileiro estava no fundo do mar. Com o movimento das placas tectônicas, essa região se elevou passando a integrar a terra firme (MALVEZZI, 2007). Já no último período glacial, há cerca de 10.000 a 8.000 anos, essas terras eram muito chuvosas, possuía vegetação semelhante à Mata Atlântica, com a presença de animais de grande porte como o Glypoton, uma espécie de tatu que tinha o tamanho de um fusca (SCHISTEK; CARVALHO, 2013). Com o fim da era glacial, fatos paleogeográficos e paleoecológicos desencadearam "uma dinâmica ambiental que possibilitou a mudança climática do clima tropical, mais úmido para o mais seco, semiárido, formando as vegetações da Caatinga e do Cerrado no Brasil"' (SCHISTEK; CARVALHO, 2013, p. 24).

As diferenças se acentuaram, a vegetação ficou mais rala, surgiram animais menores e apenas um rio passou a cruzar o Semiárido, o São Francisco (MALVEZZI, 2007), mas veremos adiante que a região tem acesso a outras bacias hidrográficas. Essas mudanças climáticas não tornaram o território menos fértil, o bioma caatinga já mostrava, nesse período, sua resistência. E hoje, de acordo com a delimitação oficial de 2005, ocupando uma área de 969.589,4 km² entre os estados de Alagoas, Bahia, Ceará, Paraíba, Pernambuco, Piauí, Rio Grande do Norte e Sergipe, além do norte de Minas Gerais (SCHISTEK, CARVALHO, 2013), estudos mostram as potencialidades e possibilidades de vida digna para os povos que habitam a região.

É preciso destacar que apesar do Semiárido ocupar grande espaço da região Nordeste, este abrange também uma parte da região Sudeste do Brasil. Desse modo, utilizar a palavra "Nordeste" para se referir à região Semiárida acaba levando à uma homogeneidade equivocada. Bem como, utilizar a expressão "sertão nordestino" para 
referir-se ao Semiárido brasileiro é algo inapropriado (MALVEZZI, 2007), já que nem todo território Semiárido localiza-se no Nordeste. Além disso, o termo "sertão" ou "sertões" é entendido como "sinônimos tradicionais de lugares distantes, inacessíveis, espaço do atraso e das populações rústicas” (MALVEZZI, 2007, p. 9), existindo assim, vários sertões pelo Brasil.

Voltando às características da região, de acordo com o Instituto Nacional do Semiárido - INSA (2011), essa é uma área de grande biodiversidade, onde foram identificados mais de 600 tipos de árvores. Se comparado com toda a Europa, representa um número significativo, já que nesse continente apenas 100 espécies foram identificadas. "Existe uma grande variedade de matas na caatinga (por exemplo: caatinga densa, arbustiva) caracterizando grande variabilidade deste ambiente, o que enseja a denominação, no plural, de caatingas" (p. 4). O INSA ainda salienta que "a marca da região semiárida é a heterogeneidade de seus geoambientes ou de suas paisagens" (p. 4).

Segundo Andrade (1998 apud CARVALHO 2004), essa heterogeneidade apresenta "grandes pediplanos, drenados pelos principais rios da região - Rio São Francisco, Parnaíba, Piranhas-Açu, Jaguaribe, etc. - ora com serras e chapadas que se alteiam sobre o pediplano e apresentam um clima úmido e sub-úmido" (p. 14), áreas conhecidas como brejos. Para Malvezzi (2007), a caatinga possui boa capacidade de regeneração, sendo "perfeitamente adaptada ao clima e aos solos locais. É um erro considerá-la como um bioma pobre em biodiversidade vegetal e animal, uma espécie de deserto" (p. 56-57).

Essa última proposição de Malvezzi (2007) se dá pelo fato de algumas características do Semiárido serem apontadas de modo estereotipado. Em contraponto à variedade ambiental, descrita anteriormente, a região apresenta-se muitas vezes ressequida e desnuda com aparência cinza, aspecto que concebe a nomenclatura caatinga, originária da língua indígena tupi-guarani, que quer dizer mata branca. "Este feitio geral de paisagem adusta e hostil durante a maior parte do ano é tomado por muitos como desolador, decerto em função da aparência sem vida da maioria das plantas, do calor escaldante e da luminosidade excessiva" (MACIEL; PONTES, 2015, p. 20).

Como as chuvas no Semiárido brasileiro são irregulares no tempo, no espaço e no volume de precipitação (CARVALHO, 2004) são frequentes os períodos de seca que acometem a região. Para o INSA (s.d.), a seca é "um fenômeno que ocorre naturalmente 
quando a precipitação registrada é significativamente inferior aos valores normais, provocando um sério desequilíbrio hídrico que afeta negativamente os sistemas de produção dependentes dos recursos da terra" (p. 1). Os resultados desse fenômeno da natureza são comumente vistos em jornais, produções fílmicas e literárias com imagens de chão rachado, carcaça de cabeça de gado, magreza e fome nas pessoas e animais do Semiárido.

De acordo com Albuquerque Júnior (1999), um fator vai agravar e substanciar a imagem negativa desse território. Entre 1877 a 1879, uma seca teve repercussão nacional pela imprensa, atingiu setores dos proprietários de terra que conseguiram, junto ao Parlamento do Brasil, grande quantidade de recurso para superar os problemas advindos da estiagem prolongada. Tem-se então, a descoberta de uma arma poderosa, a seca servia "como um tema que mobilizava, que emocionava, que podia servir de argumento para exigir recursos financeiros, construção de obras, cargos no Estado, etc." (p. 58). Desse modo, "as bancadas nortistas conseguem incluir, já na Constituição de 1891, o artigo $5^{\circ}$, que obrigava a União a destinar verbas especiais para o socorro de áreas, vítimas de flagelos naturais, abrangendo aí as secas" (ALBUQUERQUE JÚNIOR, 1999, p. 70).

Esse autor vai além, afirmando que com a criação de órgãos como a Inspetoria de Obras Contra as Secas - IOCS, em 1909, que torna-se tempos depois o Departamento Nacional de Obras Contra as Secas - DNOCS, os intelectuais e políticos ligados a essas instituições "tentam construir uma imagem e um texto único, homogêneo para a região, acabando com os vários Nordestes que entupiam as livrarias, uns sinceros, outros não. O Nordeste devia ser visto e lido numa só direção para que seu efeito de verdade fosse eficiente politicamente" (ALBUQUERQUE JÚNIOR, 1999, p. 70). Desse contexto derivam os termos "indústria da seca" e "combate à seca", ambos voltados para o assistencialismo e para criação de políticas paliativas que não vão "ao fundo das questões estruturais da pobreza e do atraso sócio-econômico do Semiárido" (CARVALHO, 2011, p. 178).

A literatura e o cinema contribuem no discurso distorcido sobre Semiárido com produções como o livro Os sertões - campanha de Canudos (1902) de Euclides da Cunha, um marco na produção literária do país, considerado por Debs (2007) como a primeira representação histórico científica da região Semiárida presente no Nordeste e um dos "mitos fundadores da sociedade brasileira" (p. 26). Em diversos momentos dessa obra, Euclides da Cunha descreve um sertão como o único no Brasil e com 
aspectos de deserto, monótono, tórrido, que maltrata as pessoas que nele vivem. Apesar de explicar, em algumas passagens da obra, que escrevia suposições, como disse ainda no capítulo sobre a terra: "O que se segue são vagas conjecturas. [...] O que escrevemos tem o traço defeituoso dessa impressão isolada, desfavorecida, ademais, por um meio contraposto à serenidade do pensamento, tolhido pelas emoções da guerra" (CUNHA, 2000, p. 27-28), Os sertões é considerado, por algumas pessoas, como um importante auxílio na compreensão do homem sertanejo e do Semiárido, ampliando o modo de entender a cultura brasileira (BARONI, 2011).

Na literatura, outras produções como O Quinze (1930) de Raquel Queiroz e Vidas Secas (1938) de Graciliano Ramos prosseguem abordando aspectos semelhantes da região Semiárida. Em consequência, obras cinematográficas, intensificadas a partir do Cinema Novo, em 1960, e inspiradas nesses escritos, começam a reproduzir as mesmas imagens do Semiárido, surgindo produções como Guerra de Canudos (1997) de Sérgio Rezende, Nordeste Sangrento (1963) dirigido por Wilson Silva e Vidas Secas (1963) de Nelson Pereira dos Santos. Tais filmes trazem a ideia de que essa região nordestina é permeada pela violência, pela seca que castiga animais e pessoas da região, obrigando-as a migrar, o que impossibilita a estadia digna e o plantio sustentável por conta da falta de água.

Esta, como um recurso hídrico, torna-se então um foco da política compensatória salientada por Albuquerque Júnior (1999). Ações emergenciais para "combater a seca" passam a ser constantes, marcadas pela construção de grandes obras hídricas no interior nordestino como o açude do Cedro de Quixadá, no Ceará, na década de 1880 - 1890 (DNCOS, [s.d.]) e a barragem do açude de Cocorobó, localizada em Canudos-BA e construída entre 1951 a 1967 (DNOCS, [s.d.]). Outra grande obra é a Usina Hidrelétrica de Sobradinho entre 1973 a 1979, que segundo a Companhia Hidrelétrica do São Francisco - CHESF, responsável pelo empreendimento, tem a pretensão de, além da função de gerar energia elétrica, ser a principal fonte de regularização dos recursos hídricos da região (CHESF, [s.d.]).

Entretanto, contrariando a lógica do "combate" e "indústria da seca" a partir dos anos de 1980 se intensificam no Semiárido ideias e ações que visualizam as potencialidades e viabilidades dessa região, através da Proposta da Convivência com o Semiárido, encabeçada por organizações populares, comunidades eclesiais de base (CEBs) e movimentos sociais. Malvezzi (2007) salienta que "o segredo da Convivência está em compreender como o clima funciona e adequar-se a ele. Não se trata mais de 
acabar com a seca, mas de adaptar-se de forma inteligente" (p. 12).

Para Carvalho (2004), começa a ganhar destaque no Semiárido "as ideias do desenvolvimento integrado sustentável, que vai se efetivando aqui e ali, através da agroecologia; das cisternas familiares de captação da água de chuva nos telhados, garantindo água de chuva para o consumo humano e também visando a produção" (p. 23).

Fica explícito que, com o passar dos anos, a região Semiárida ganha duas formas distintas de interpretação tendo em ambas a água em evidência. Percebe-se também que nessas concepções o recurso hídrico está imbricado em uma divergência inquietante, ora marcado pela ausência, ora identificado pela presença satisfatória. Desse modo, pretendemos analisar como a água se torna um fator determinante para a construção desses diferentes discursos sobre a mesma região. Para isso, utilizaremos literaturas, livros didáticos e produções jornalísticas que versam sobre o Semiárido, sabendo que tal recurso hídrico é de suma importância para a vida dos povos no Semiárido e tendo a consciência de que elucidar as características do clima semiárido e do bioma caatinga é uma das maneiras de encontrar ações e políticas eficazes para o bem viver nessas terras.

\section{Água no Semiárido: presença satisfatória, acesso urgente}

A proposta da Convivência com o Semiárido despertou interesse de órgãos, instituições e pessoas da sociedade civil em entender e conhecer esse clima, muitos estudos foram/são feitos apontando aspectos pouco divulgados, como veremos adiante. Em relação à água, pesquisadores mostram que o Semiárido brasileiro é o mais chuvoso do mundo com precipitação entre 200 a $800 \mathrm{~mm}$ por ano (CARVALHO, 2004; MALVEZZI, 2007), um número significativo já que, em outras regiões semiáridas do planeta, as precipitações ficam em torno de 250 a $700 \mathrm{~mm}$ anuais (CIRILO, FERREIA e CAMPELLO NETO, 2007 apud PONTES, 2010).

Apesar disso, comparando com as demais regiões do Brasil, o Nordeste é o território que detém menor quantidade de água no país, 3\%, enquanto o Norte tem cerca de $70 \%$, o Centro Oeste 15\%, o Sul e Sudeste 6\%. De acordo com os estudos da Organização das Nações Unidas, ONU (apud MALVEZZI, 2007), nem mesmo Pernambuco, o estado com menor quantidade de água por pessoa, em média $1.270 \mathrm{~m}^{3}$, se enquadra na faixa de escassez, caracterizada, quando a quantidade está a abaixo de 
$1.000 \mathrm{~m}^{3}$. O Instituto Regional da Pequena Agropecuária Apropriada, IRPAA ([s.d.]) afirma que a precipitação de água neste Semiárido é suficiente para garantir a sobrevivência humana e animal, mesmo com chuvas irregulares no tempo e no espaço (SCHISTEK, CARVALHO, 2013).

Percebemos, portanto, que o problema não está na ausência da chuva, como relata Euclides da Cunha (2000), quando salienta que os leitos que armazenam a água no sertão encontram-se, na maioria das vezes, secos e a chuva, para enchê-los, é breve e rara. $\mathrm{Na}$ verdade, a questão preocupante se desloca para a quantidade de água que é evaporada, os números atingem cerca de $3.000 \mathrm{~mm}$ por ano (ASA BRASIL, [s.d.]), muito maiores do que os dados de precipitação, provocando um déficit hídrico desafiador. Além disso, o subsolo Semiárido do Brasil é formado por $70 \%$ de rochas cristalinas "o que dificulta a formação de mananciais perenes e a potabilidade da água, normalmente salinizada" (MALVEZZI, 2007, p. 10).

Elucidada essas questões, a busca passa a ser por tecnologias que armazenem a água que cai da chuva e que impeçam a evaporação da mesma. Para Malvezzi (2007) fica claro que o problema não é a falta de água, mas o acesso a ela. Ainda segundo ele, "desde que começaram a surgir grandes obras de armazenamento de água na região Semi-árida, ela também está apropriada, seja dentro de propriedades privadas, seja dentro de mananciais que não têm adutoras para conduzir essa água até as populações mais necessitadas" (p. 62).

De acordo com o IRPAA ([s.d])

\begin{abstract}
(...) ainda não é comum a preocupação por parte dos governos de captar e armazenar a água das chuvas com estruturas à prova da evaporação e próximo às casas dos lavradores e lavradoras. Necessita-se de um plano de infraestrutura hídrica descentralizada. Grande parte da população ainda não possui e não tem condições de construir seus reservatórios com recursos próprios. Esses fatores contribuem para que no período de seca, a população fique na dependência do carro-pipa e vulnerável à manipulação por parte de alguns políticos (p.2).
\end{abstract}

Tal contexto pode ser visto atualmente em produções musicais, como a canção “Chuva de Honestidade” (2016), de autoria do cantor Flávio Leandro:

Quando o ronco feroz do carro pipa, cobre a força do aboio do vaqueiro

Quando o gado berrando no terreiro, se despede da vida do peão

Quando verde eu procuro pelo chão, não encontro mais nem mandacaru

Dá tristeza ter que viver no sul, pra morrer de saudades do sertão 
Eu sei que a chuva é pouca e que o chão é quente,

Mas, tem mão boba enganando a gente, secando o verde da irrigação

Não! Eu não quero enchentes de caridade, só quero chuva de honestidade

Molhando as terras do meu sertão

Eu pensei que tivesse resolvida, essa forma de vida tão medonha Mas, ainda me matam de vergonha, os currais, coronéis e suas cercas Eu pensei nunca mais sofrer da seca, no nordeste do século vinte e um Onde até o voo troncho de um anum, fez progressos e teve evolução

Israel é mais seco que o nordeste, no entanto se veste de fartura Dando força total a agricultura, faz brotar folha verde no deserto Dá pra ver que o desmando aqui é certo, sobra voto, mas, falta competência

Pra tirar das cacimbas da ciência, água doce que serve a plantação

A música denuncia possíveis irregularidades nas políticas públicas implantadas no Semiárido, anuncia a presença de coronéis e de suas artimanhas no controle e posse da água ainda nos dias atuais e questiona a construção de estratégias e estudos que façam a região Semiárida brasileira avançar, como acontece em outros lugares que apresentam mesmo clima. Além da literatura, já mencionada neste trabalho, alguns livros didáticos, em número ainda reduzido, têm se encarregado de agregar outros olhares para o Semiárido. A coleção Educação de jovens e adultos no Semi-árido brasileiro (2007) traz assuntos como a diversidade da fauna e flora da região, reflexões sobre as identidades sertanejas e acesso à água e à terra numa perspectiva voltada à discussão e formação política dos alunos. Essa obra também aborda a "indústria da seca" e afirma que grupos políticos e econômicos estão "divulgando uma situação de calamidade pública, essa elite consegue ajuda governamental - como anistia de dívidas, verbas de emergência e renegociação de empréstimos. Tais auxílios nem sempre beneficiam a população afetada pela estiagem" (EDUCAÇÃO, 2007, p. 57).

\section{Água no Semiárido: escassez e miséria}

Como mencionamos anteriormente, ainda são poucos os livros escolares que se propõem a elucidar as potencialidades do Semiárido brasileiro. Para Schistek e Carvalho (2013), nessas produções, a região tem sido apresentada "pela negação, pela hostilidade e pela estereotipia, para com sua natureza, seus ícones formadores da identidade cultural-territorial e de suas gentes. Nessa negação, a caatinga aparece como 'vegetação 
morta', o sertanejo como 'rude', o índio como 'hostil' etc.” (p. 15).

Em algumas dessas obras, podemos perceber que a nomenclatura Semiárido também não é identificada. Nos livros Segredos da Bahia (DIEZ, 1998) e História: Bahia (SILVA; CHIANCA, 2004) são utilizados os termos "interior" ou "sertão" para se referir às regiões afastadas no litoral baiano. De acordo com Carvalho (2012), o Semiárido é apenas "um dos tantos 'sertões' presentes na territorialidade brasileira" (p. 87). Assim como essas produções didáticas, o livro Histórias nas trilhas da Bahia (RIBEIRO, 2008) não problematiza a questão da água no Semiárido, apesar de uma página da obra se referir à transposição do Rio São Francisco e fazer menção ao combate à seca.

\begin{abstract}
A transposição do rio São Francisco tem sido justificada como uma forma de combater a seca. Os que são contrários a esse projeto dizem que ele traz problemas ambientais e sociais tão grande que não compensaria fazer a transposição. Afirmam ainda que existem outras alternativas mais baratas e eficientes para resolver o problema da seca no Nordeste (RIBEIRO, 2008, p. $55)$.
\end{abstract}

É perceptível que esse texto não aprofunda a reflexão sobre a transposição das águas do rio São Francisco, o que pode deixar o leitor sem a compreensão precisa do fato, além de não promover em sala de aula um debate profícuo. Esses livros se dedicam, majoritariamente, a tratar de assuntos relacionados a cidades litorâneas e, quando abordam o "interior" da Bahia, fazem menção a temas conhecidos, como o vaqueiro, a Guerra de Canudos e Lampião.

Já o conteúdo dos jornais sobre a região segue um raciocínio semelhante. Geralmente, as reportagens, nos mais variados veículos de comunicação, são produzidas, ressaltando a imagem do Semiárido como um lugar ressequido. Um exemplo foi a matéria exibida, no dia 16 de fevereiro de 2017, no programa Bom Dia Brasil, da Rede Globo, intitulada "Chuva no Nordeste não resolve problema da seca e causa transtorno". Os repórteres, em diferentes lugares da região, mostraram onde havia chovido em abundância, mas alegavam que a precipitação não solucionou a estiagem, pelo contrário, trouxe problemas urbanos e fez mais de 150 municípios continuarem em situação de emergência. Por não fazer alusão à característica do Semiárido de possuir chuvas irregulares no tempo e espaço, essa reportagem deixa entender que nem mesmo a água que cai do céu é suficiente para resolver os problemas de escassez na região.

Visto dessa forma, ou o Semiárido é um território inabitável ou a resolução dos seus agraves deve vir, não de condições naturais como a chuva, mas talvez, de ações 
humanas como as grandes obras governamentais. Para corroborar essa suposição, ao final da matéria, a apresentadora e jornalista Ana Paula Araújo comenta: "É, tem que melhorar a estrutura para captar a água que agora está caindo por lá" (CHUVA, 2017). A afirmação é propositiva, mas não faz parte do conteúdo da reportagem, o que acaba por deixá-la solta e sem provocações ao telespectador.

\section{Considerações finais}

A representação do Semiárido brasileiro é marcada por dois discursos sobre a presença da água nesse território, tendo como marco, de um lado, a proposição do combate e indústria da seca que encabeçam a ideia de que essa região não tem condições hídricas suficientes para alavancar seu desenvolvimento, explorando a imagem que, mesmo quando chove, sua população continua sofrendo e tendo consequências negativas, tais como a fome, a migração, a pobreza e a dependência das ações estatais.

De outro lado, embasado na ideia de convivência, há o entendimento de que o Semiárido é um lugar viável, onde, mesmo com chuvas inconstantes, é possível dessedentar animais, plantar e saciar as necessidades humanas. O que está ausente não é a água, mas as condições de possuí-la, seja por meio de tecnologias acessíveis, de políticas públicas condizentes ou democratizando o acesso aos reservatórios que estão sob o domínio de poucos.

Além disso, percebemos que a presença satisfatória da água no Semiárido brasileiro não é tema de muitos livros didáticos, tão pouco de reportagens jornalísticas, o que leva a sociedade à falta de conhecimentos das condições e estudos hídricos realizados por órgãos de importância para a região, como o INSA. A persistência em tratar o Semiárido pela ótica da falta de água permite que se forme um imaginário social permeado pela estereotipia e que nega o acesso das pessoas à informação e conhecimento das pesquisas e avanços que acontecem nesse território. 


\section{Referências}

ALBUQUERQUE JÚNIOR, Durval Muniz de. A invenção do Nordeste e outras artes. Recife: FJN, ed. Massangana; São Paulo: Cortez, 1999.

BARONI, Alice. Guerra de Canudos: uma leitura euclidiana. In: $\mathbf{8}^{\mathbf{o}}$ Encontro Nacional de História da Mídia, 2011, Guarapuava PR. Anais: ALCAR. Disponível em: <http://www.ufrgs.br/alcar/encontros-nacionais-1/8o-encontro-2011-1/artigos/ Guerra\% 20de\%20Canudos\%20uma\%20leitura\%20euclidiana.pdf/view > Acesso em 22.04.2016.

CARVALHO, Luzineide Dourado. A contribuição da educação contextualizada para a relação natureza, cultura e território no semiárido brasileiro. In: Educação contextualizada fundamentos e práticas. Juazeiro-BA: UNEB/Departamento de Ciências Humanas- Campus III/UNEB/NEPEC-SAB/MTC/CNPQ/INSA, 2011.

A emergência da lógica da "convivência com o semi-árido" e a construção de uma nova territorialidade. In: Educação para a convivência com o semiárido: reflexões teórico práticas. Juazeiro-BA: Secretaria Executiva da Rede de Educação do Semiárido Brasileiro, 2004.

Natureza, território e convivência: novas territorialidades no Semiárido brasileiro. Jundiaí: Paco Editorial, 2012

CHESF. Sobradinho - Descrição e aproveitamento de Sobradinho. [s.d.], não paginado. Disponível em:

<https://www.chesf.gov.br/SistemaChesf/Pages/SistemaGeracao/ Sobradinho.aspx>. Acesso em 09. Abr .2017

CHUVA de honestidade. Disponível em: <https://www.youtube.com/watch?v= CUUNteLy6BQ>. Acesso em 04. Jun. 2017

CHUVA no Nordeste não resolve problema da seca e causa transtorno. 2017. Disponível em: <http://g1.globo.com/bom-dia-brasil/noticia/2017/02/chuva-nonordeste-nao-resolve-problema-da-seca-e-causa-transtorno.html>. Acesso em 26. Jun. 2017

CUNHA, Euclides da. Os Sertões: campanha de Canudos. 39ª ed. Rio de Janeiro: Publifolha, 2000.

DEBS, Sylvie. Cinema e literatura no Brasil: os mitos do sertão, emergência de uma identidade nacional. Fortaleza: Interarte, 2007.

DIEZ, Albani Galo. Segredos da Bahia, 4. História. São Paulo: FTD, 1998

DNOCS. Açude Cedro. [s.d.], não paginado. Disponível em:

<http://www.dnocs.gov.br/barragens/ cedro/cedro.htm>. Acesso em 09. Abr .2017

Açude Cocorobó. [s.d.], não paginado. Disponível em: 
<http://www.dnocs.gov.br/barragens/ cocorobo/cocorobo.htm>. Acesso em 09. Abr .2017

EDUCAÇÃO de jovens e adultos no Semi-árido brasileiro. Org: Ângelo Custódio Neri de Oliveira e Ivânia Paula Freitas de Souza. In: Módulo III e Móduo IV. São Paulo: Peirópolis, 2007.

INSA. Recursos hídricos em regiões áridas e semiáridas. Editores, Salomão de Sousa Medeiros, Hans Raj Gheyi, Carlos de Oliveira Galvão e Vital Pedro da Silva Paz. Campina Grande, PB: Instituto Nacional do Semiárido, 2011. Disponível em: $<$ https://portal.insa.gov.br/images/acervo-livros/Recursos\%20H\%C3\%ADdricos\% 20em\% 20Regi\%C3\%B5es\%20\%C3\%81ridas\%20e\%20Semi\%C3\%A1ridas.pdf $>$. Acesso em 30. Maio. 2017

IRPAA. Apresentação: viver no Semiárido é aprender a Conviver! [s.d.]. Disponível em: <http://www.irpaa.org/modulo/portugues>. Acesso em 22. Set .2016

Água. [s.d]. Disponível em: < http://www.irpaa.org/modulo/agua>. Acesso em 04. Jun. 2017

Elementos conceituais. [s.d]. Disponível em:

<https://rededesertificacao.insa.gov.br/ index.php/2013-02-21-14-05-04>

MACIEL, Caio; PONTES, Emílio Tarlis. Seca e convivência com o Semiárido: adaptação ao meio e patrimonialização da caatinga no Nordeste brasileiro. 1. Ed. Rio de Janeiro: Consequência editora, 2015.

MALVEZZI, Roberto. Semi-árido uma visão holística. Brasília: Confea, 2007.

RIBEIRO, Miriam Bianca do Amaral. Histórias nas trilhas da Bahia, $4^{\circ}$ ano. São Paulo: FTD, 2008

SCHISTEK, Harald; CARVALHO, Luzineide Dourado. A formação históricogeográfica do semiárido brasileiro. In: Educação e convivência com o semiárido brasileiro: reflexões por dentro da UNEB. $2^{\text {a }}$ ed. Juazeiro-BA: UNEB/Departamento de Ciências Humanas-campus III/UNEB/NEPEC-SAB/MCT/CNPQ/INSA/Selo Editorial RESAB, 2013.

SILVIA, Lilian dos Santos; CHIANCA, Rosaly Maria Braga. História: Bahia. São Paulo: Ática, 2004

UMBUZEIRO, árvore nativa do Nordeste, socorre agricultores na seca. 2017. Disponível em: <http://g1.globo.com/jornal-nacional/noticia/2017/03/umbuzeiroarvore-nativa-do-nordeste-socorre-agricultores-na-seca.html >. Acesso 22. Abr .2017 